\title{
Evaluación de la calidad docente y promoción del profesorado (IV). Legislación Universitaria española (b): de la Ley de Reforma universitaria (1983) a la Ley Orgánica de universidades (2002). ( $2^{\mathrm{a}}$ parte)
}

\author{
Evaluation of teaching and faculty promotion (IV). University \\ spanish legislation (b): from the Law of university reformation (1983) \\ to the organic law of universities (2002). ( $2^{\text {ond }}$ part)
}

Josep Carreras

Departament de Ciències Fisiològiques I. Facultat de Medicina. Universitat de Barcelona. Barcelona.

\section{PROYECTOS DE REFORMA DE LA LRU (1991-1999)}

Siete años después de la aprobación de la LRU existía un consenso bastante generalizado sobre la necesidad de modificar el sistema de selección del profesorado, sobre todo como consecuencia del alto grado de endogamia que se había desarrollado, y de la adulteración que había sufrido la figura del profesor asociado. Por ello, el Ministro de Educación Javier Solana sugirió en el primer pleno del Consejo de Universidades del curso 1991-92 la conveniencia de debatir antes de finalizar el año los retoques que necesitaba el título $\mathrm{V}$ de la LRU relativo al profesorado ${ }^{117}$, y a tal fin presentó sus propuestas en una reunión del Consejo celebrada a mitad del mes de diciembre. La reforma propuesta por el ministro consistía, esencialmente, en el establecimiento de un sistema de habilitación para el acceso al cuerpo de profesores titulares de universidad, aunque serían las universidades las que seleccionarían y adscribirían los profesores habilitados a las plazas concretas ${ }^{118}$. Desde el primer momento, algunos responsables uni-

\footnotetext{
Correspondencia:

Josep Carreras Barnés

Departament de Ciències Fisiològiques I.

Facultat de Medicina. Universitat de Barcelona. Barcelona.

Casanova 143. 08036 Barcelona.

FAX: 934035882

E-mail: jcarrera@medicina.ub.es
}

versitarios, como los rectores de las cuatro universidades públicas catalanas, se mostraron en desacuerdo con la propuesta ministerial, por interpretar que la misma conduciría a una disminución de la autonomía de las universidades ${ }^{119}$; mientras que algunas autoridades académicas de Madrid no veían mal la fórmula de la habilitación ${ }^{120}$. Por otra parte, el Grupo Parlamentario Popular había elaborado una propuesta de modificación de la normativa relativa al profesorado que no difería substancialmente de las fórmulas propuestas por el gobierno socialista ${ }^{121}$. Pero, el Ministerio abandonó la iniciativa propuesta, y en el mes de abril de 1992 presentó al Consejo de Universidades una nueva propuesta según la cual únicamente se modificaba el número de miembros de las comisiones de acceso a los cuerpos docentes universitarios propuestos por las universidades. Las mismas propondrían sólo el presidente, y los cuatro vocales, que incluirían investigadores del CSIC, serían elegidos por sorteo. El proyecto ministerial fue aprobado por el pleno del Consejo de Universidades, si bien manifestaron su disconformidad los rectores de las universidades públicas catalanas y representantes de la Generalitat de Catalunya ${ }^{122}$.

En el mes de junio Solana fue nombrado Ministro de Asuntos Exteriores y el hasta entonces Secretario de Estado de Educación y Ciencia, Alfredo Pérez Rubalcaba, pasó a desempeñar la cartera ministerial de educación. Pero ello no impidió que en el mes de agosto el Consejo de Ministros aprobara finalmente el proyecto de Ley sobre actualización de la LAU que fue 
remitido a las Cortes el mes de septiembre ${ }^{123}$. El texto, aparte de reducir a uno el número de miembros de las comisiones para el acceso a las cuerpos docentes designados por las universidades, contemplaba la nueva figura del profesor colaborador, que podía ser contratado por las universidades para impartir docencia en determinadas áreas de conocimiento (Art.1) y devolvía a su sentido original la figura del profesor asociado. Los diversos grupos parlamentarios presentaron casi doscientas enmiendas, entre ellas dos a la totalidad: una del Grupo Parlamentario Vasco, solicitando la devolución del proyecto de Ley al gobierno y otra del Grupo Popular con texto alternativo ${ }^{124}$. El Partido Popular propuso que el ingreso en los cuerpos docentes universitarios se hiciera previa superación un unas pruebas de habilitación resueltas por comisiones de carácter nacional. Los habilitados quedarían en situación de expectativa de nombramiento hasta que ganasen un plaza concreta de una universidad mediante concurso de méritos. Después de que el pleno del Congreso de Diputados rechazara esta dos enmiendas ${ }^{125}$, el proyecto de Ley, previo informe de la Ponencia ${ }^{126}$, pasó a ser discutido por la Comisión de Educación y Cultura, que emitió su dictamen a finales del mes de diciembre ${ }^{127}$ después de introducir veintinueve enmiendas ${ }^{128,129}$. Previa aprobación por el Pleno del Congreso en febrero de $1963{ }^{130,131}$, el proyecto de Ley pasó al Senado, que introdujo algunas nuevas enmiendas ${ }^{132}$ y lo aprobó en Pleno a finales de marzo ${ }^{133,134}$. El proyecto de Ley debía volver al Pleno del Congreso de Diputados para su aprobación definitiva; pero la disolución de las Cortes, decretada en abril con motivo de la convocatoria de elecciones legislativas, interrumpió su tramitación y su aprobación parlamentaria definitiva.

El nuevo gobierno socialista surgido de las elecciones de junio de 1993, en el que figuraba Gustavo Suárez Pertierra como Ministro de Educación y Ciencia, elaboró un nuevo texto del proyecto de ley de actualización de la LRU que remitió a las Cortes en mayo de $1994^{135}$. Según el nuevo texto, la universidades seguirían designando a dos de los miembros de las comisiones de los concursos de acceso a los cuerpos de profesorado universitario; pero se establecerían mecanismos para controlar la calidad docente e investigadora de los aspirantes desde el principio de su carrera académica. Para concursar a plazas de profesor titular de universidad, se establecía como prerrequisito acreditar, ante sendas comisiones específicas, cinco años de docencia y seis de actividad investigadora. Por otra parte, los aspirantes a cátedras deberían acreditar dos quinquenios de docencia y dos sexenios de investigación. Dentro de los profesores contratados, junto a los ayudantes, el proyecto de ley creaba la figura de profesor ayudante, necesariamente doctor, y de profesor colaborador. La interpretación que los principales partidos políticos de la oposición hicieron de la renuncia gubernamental a la reducción del número de miembros de las comisiones de designación directa por las universidades apuntaba a que la misma fue rechazada por el grupo parlamentario de CiU cuando se tramitó el anterior proyecto de ley, y el grupo socialista precisaba de los votos del grupo catalán para sacar adelante el nuevo texto ${ }^{136}$.

El nuevo proyecto de Ley, que el gobierno había decidido tramitar por el procedimiento de urgencia por el Congreso de Diputados el mes de junio, recibió un fuerte rechazo por parte de numerosos profesores y Juntas de Gobierno de diversas universidades, así como por parte de los partidos políticos de la oposición (incluido $\mathrm{CiU}$ ) y de los sindicatos. Por ello el gobierno acordó ampliar el plazo de presentación de enmiendas y tramitar el proyecto por el procedimiento ordinario. En total se presentaron casi trescientas enmiendas ${ }^{137}$, entre ellas dos a la totalidad con textos alternativos; una del Grupo Federal IU-IC y otra del Grupo Popular, que incluía un texto semejante al presentado anteriormente ${ }^{124}$. En el mes de septiembre se inició el debate parlamentario y, después de que el Pleno del Congreso rechazara las propuestas alternativas del Partido Popular y de Izquierda Unida ${ }^{138}$, el proyecto de Ley pasó a la Comisión de Educación y Cultura. En junio de 1995, producido un cambio de gobierno, el nuevo Ministro de Educación y Ciencia, Jerónimo Saavedra, hizo su primera comparecencia ante dicha Comisión. En su discurso el ministro pasó de puntillas sobre el proyecto de ley de actualización de la LRU, y dio a entender las escasas esperanzas que tenía de que el mismo pudiera aprobarse antes de la disolución de la legislatura ${ }^{139}$. Y así sucedió; al tener lugar las elecciones generales en 1996,el proyecto de Ley de actualización de la LRU no había sido discutido por el Pleno del Congreso de los Diputados.

Destaquemos, para acabar este apartado, que el doble mecanismo de evaluación de la actividad docente y de la actividad investigadora de los profesores se mantuvo en los proyectos de modificación de la LRU elaborados por el gobierno socialista. El primer proyecto presentado por el Gobierno a las Cortes ${ }^{123}$ proponía una modificación del artículo 46 de la LRU en el sentido de indicar que la evaluación de las actividades de investigación realizada con fines retributivos correría a cargo de una Comisión Nacional nombrada por el Ministerio de Educación y Ciencia; no 
indicaba quien debería valorar las funciones docentes. Pero en el texto aprobado por el Pleno del Congreso de los Diputados ${ }^{131}$ se precisaba que dichas funciones serían apreciadas por las propias universidades. El segundo proyecto de modificación de la LRU ${ }^{135}$ exigía que los candidatos para el acceso a los cuerpos docentes universitarios hubieran obtenido, al menos, una evaluación positiva de sus actividades, docente durante un quinquenio e investigadora durante un sexenio, en el caso de las plazas de profesor titular de universidad, y dos evaluaciones positivas, de una y otra actividad, en el caso de las plazas de catedrático de universidad. Las actividades docentes serían evaluadas por las propias universidades, conforme a procedimientos y sistemas previa y estatutariamente determinados, dentro del marco de criterios generales y homogéneos establecidos por el Consejo de Universidades. Las actividades de investigación serían evaluadas por una Comisión Nacional nombrada por el Ministerio de Educación y Ciencia.

\section{LEY ORGÁNICA DE UNIVERSIDADES (LOU)}

Esperanza Aguirre, Ministra de Educación y Cultura del gobierno del Partido Popular surgido de las elecciones de 1996, en la apertura del curso académico 1996-97 señaló ya la necesidad de modificar la LRU en tres aspectos: sistema de selección de los estudiantes, acceso a la función docente y órganos universitarios de gobierno y gestión. En marzo de 1997, el gobierno declaró que estaba preparado un anteproyecto de Ley de modificación de la LRU que consideraba la posibilidad de establecer contratos laborales para el profesorado y que definía un nuevo modelo de carrera académica con cinco niveles: becarios y ayudantes, profesores asistentes, profesores permanentes - ya funcionarios - profesores titulares de universidad y catedráticos. El paso a la categoría de profesor funcionario se haría mediante concurso-oposición con tres ejercicios, juzgados por un tribunal con el presidente nombrado por la universidad respectiva y cuatro vocales elegidos por sorteo. Sin embargo, la presentación de dicho anteproyecto se fue demorando, por lo cual los rectores de diversas universidades en los discursos de inauguración del curso académico manifestaron públicamente su malestar. Como respuesta a tales manifestaciones, en octubre de 1997 el Gobierno creó una comisión mixta con representantes de la administración y de la Conferencia de Rectores (CRUE), a fin de discutir los temas considerados más urgentes: la reforma de la carrera docente y la reforma de los planes de estudio. Finalizada la tarea de dicha comisión, en enero de 1998 el Ministerio dio a conocer un anteproyecto de reforma del Título V de la LRU, relativo al profesorado, que reintroducía el concurso de méritos para cubrir plazas antes de convocar oposiciones y apuntaba la creación de nuevas figuras docentes: la de profesor colaborador no doctor y la de profesor contratado doctor ${ }^{140}$. Ante la reacción adversa de los rectores, que consideraban que el texto no se avenía a lo pactado en la comisión, y de los sindicatos, el Ministerio decidió rápidamente renunciar al mencionado concurso de méritos y proceder a la elaboración de un nuevo texto. Dado el retraso en la presentación de dicho texto, en mayo de 1998 el grupo parlamentario del PSOE presentó a las Cortes una propuesta en la que se pedía la reforma del Título V de la LRU; pero la misma fue rechazada por el Congreso de Diputados ${ }^{141}$.

En el inicio del curso académico 1998-99, la ministra Aguirre se comprometió a presentar el proyecto de ley a las Cortes antes de fin de año, y a mitad del mes de diciembre se dio a conocer el texto elaborado por la Secretaría de Estado de Universidades ${ }^{142}$. De acuerdo con el mismo, se modificaba la composición de los tribunales encargados de juzgar los concursos (en los que se reducía a uno el número de miembros designados por las universidades), y los ejercicios de las oposiciones a profesor titular incorporaban una prueba de exposición de un tema (elegido por el tribunal entre tres) y otra de carácter práctico. Por otra parte, se mantenía la figura de profesor asociado y se creaban dos nuevas figuras de profesor contratado: el profesor contratado doctor y el profesor colaborador no doctor. El texto, que había sido negociado con los nacionalistas catalanes, fue duramente criticado por los partidos políticos y por los sindicatos, que acusaron al gobierno de intentar reformar la LRU prescindiendo de ellos.

El cambio de la cartera ministerial, que en enero de 1999 pasó a estar ocupada por Mariano Rajoy hasta entonces Ministro de las Administraciones Públicas, determinó una nueva demora en la presentación del proyecto de ley a las Cortes. El nuevo ministro decidió regular primero la precaria situación en que se hallaba el profesorado contratado, dejando para más adelante la modificación de la LRU. Pero hasta finales de año el gobierno no aprobó un plan de estabilización y mejora del profesorado calificado de "apaño" por la oposición - a la vez que se comprometió a presentar el proyecto de reforma de la LRU al Congreso a finales del año 2000, para que pudiera ser aprobado en verano del año 2001.

El nuevo gobierno surgido de las elecciones legislativas del año 2000 en las que el Partido Popular obtu- 
vo mayoría absoluta, en el que figuraba Pilar de Castillo como Ministra de Educación, Cultura y Deportes, se comprometió, en el mes de junio, a modificar las cuatro grandes leyes educativas (LOGSE, LODE, LOPEG y LRU) en dos años; antes de junio del año 2001, en el caso de la LRU. En febrero de este año, el presidente de la Conferencia de Rectores ( CRUE ), con motivo de la presentación al Congreso de Diputados del "Informe Universidad 2000" (Informe Bricall) ${ }^{38}$ que hacía un análisis pormenorizado de la situación de la Universidad española y sugería las medidas que se podían aplicar para la modernización de la misma, anunció la creación del foro "Universidad y Sociedad", y pidió al Congreso que lo auspiciara como vía para escuchar las opiniones de la sociedad sobre qué aspectos de la LRU deberían modificarse en la nueva ley universitaria. En el mes de marzo, al mismo tiempo que el propio Bricall exponía al Senado las propuestas de reforma contenidas en el mencionado informe, la Generalitat de Catalunya dio a conocer otro informe ${ }^{143}$ que sobre la reforma del marco legal de las universidades había elaborado un comité constituido por más de veinte personalidades de la ciencia, la cultura, la empresa y la política. A partir de este mes comenzaron a filtrarse algunos aspectos del borrador de la ley que sobre la Universidad estaba elaborando el gobierno con la colaboración de diversos profesores universitarios. Por lo que respecta al profesorado, el gobierno pensaba establecer una prueba estatal de habilitación para acceder a los cuerpos docentes de funcionarios ${ }^{144}$. Desde el primer momento, los sindicatos más representativos de la enseñanza pública rechazaron la habilitación, por considerar que cuestionaría la autonomía universitaria e invadiría las competencias autonómicas.

En abril, la ministra Pilar del Castillo dio a conocer al Consejo de Universidades las líneas maestras del anteproyecto de Ley de Universidades ${ }^{145}$, si bien el texto correspondiente no fue remitido a los rectores y a los gobiernos de las comunidades autónomas hasta el mes de mayo ${ }^{146}$. De acuerdo con él, se suprimían las pruebas de selectividad, dejando en manos de las universidades los criterios de la admisión de alumnos; se modificaba la composición de los órganos de gobierno y de representación, así como los mecanismos de elección de las autoridades académicas; se creaban nuevas figuras de profesor contratado y se redefinían las ya existentes, y se establecía un sistema de habilitación nacional que facultaría durante un tiempo limitado para concurrir a los concursos de acceso a las plazas que convocaran las universidades. De forma inmediata, los principales partidos de la oposición y los sin- dicatos de educación manifestaron su oposición al anteproyecto y pidieron que se enlenteciera el proceso de tramitación del mismo a fin de conseguir el adecuado consenso. Por otra parte, también se manifestaron en contra asociaciones de estudiantes, diversos rectores, claustros y juntas de gobierno universitarias ${ }^{147}$, y la asamblea general de la CRUE suscribió un documento de rechazo, en el que se insistía en la necesidad de alcanzar el consenso entre las distintas fuerzas políticas, las universidades y los agentes sociales ${ }^{148}$. Ante esta respuesta, el gobierno aceptó ampliar el período de discusión del anteproyecto antes de su tramitación parlamentaria y debatir con los rectores las propuestas de modificación; a tal fin, la CRUE estableció un procedimiento de trabajo para aportar las correspondientes propuestas alternativas. Por lo que respecta al acceso del profesorado a los cuerpos docentes de funcionarios, la CRUE propuso sustituir las pruebas de habilitación estatal propuestas por el gobierno por una acreditación de méritos sin examen y sin limitación de acreditados ${ }^{149}$.

La ministra informó sobre el borrador del proyecto de Ley de Universidades a la Comisión de Educación, Cultura y Deportes del Congreso de Diputados a finales del mes de mayo ${ }^{150}$, y a la Comisión del Senado a principios de junio $^{151}$. Finalmente, el 21 de junio presentó al pleno Consejo de Universidades una nueva redacción del anteproyecto de ley con algunas modificaciones relativas a los órganos de gobierno y representación universitarios que recogían parcialmente las propuestas de los rectores ${ }^{152}$. Respecto a la selección del profesorado, se mantenía el sistema de habilitación, si bien se eliminaba la caducidad del mismo ${ }^{153}$. La CRUE consideró que sus propuestas no habían sido recogidas y manifestó su rechazo unánime al anteproyecto, a la vez que solicitó audiencia al Consejo de Estado para exponerle su opinión antes de que este Consejo presentara su informe preceptivo sobre el anteproyecto de ley ${ }^{154}$. Denegada esta petición en base a la urgencia con que tenía que informar, la Comisión Permanente del Consejo de Estado emitió un dictamen favorable, si bien hizo algunas recomendaciones de modificación ${ }^{155}$. El texto definitivo del anteproyecto de la ley - que pasó a denominarse Ley Orgánica de Universidades - fue aprobado por el Consejo de Ministros el día 27 de julio, y se publicó en el Boletín Oficial de las Cortes el día 31 del mismo mes ${ }^{156}$; estableciéndose un período de presentación de enmiendas que finalizaba el 18 de septiembre y que más tarde se amplió unos días. Entretanto, el partido socialista había elaborado un texto alternativo ${ }^{157}, \mathrm{y}$ tanto los otros partidos de la oposición como los sindi- 
catos y varias asociaciones de estudiantes habían manifestado su descontento y habían anunciado la convocatoria de movilizaciones de protesta a principios del nuevo curso académico. La CRUE había emitido un comunicado en contra del Proyecto de Ley ${ }^{158} \mathrm{y}$ en cuanto a los profesores hubo manifestaciones públicas en los dos sentidos: mientras unos apoyaban las propuestas del gobierno ${ }^{159}$, otros se pusieron totalmente en contra de las mismas ${ }^{160,161}$.

El título IX del proyecto de Ley publicado en el Boletín de las Cortes, dedicado al profesorado, establecía que el personal docente e investigador de las universidades estaría compuesto de funcionarios de los cuerpos docentes universitarios y de personal contratado (Art. 47). Los cuerpos de funcionarios seguirían siendo los cuatro ya existentes: catedráticos de universidad, profesores titulares de universidad, catedráticos de escuelas universitarias y profesores titulares de escuelas universitarias (Art. 56). El procedimiento de acceso a dichos cuerpos se articulaba en dos fases: habilitación nacional específica para cada cuerpo y área de conocimiento, y adscripción para una plaza concreta mediante concurso de acceso resuelto por la correspondiente universidad. Las pruebas de habilitación serían convocadas por el Consejo de Coordinación Universitaria, en respuesta a las necesidades de las universidades, y serían juzgados por comisiones compuestas por siete profesores del área de conocimiento correspondiente elegidos por sorteo, que deberían poseer el reconocimiento de al menos un período de actividad investigadora los profesores titulares de universidad o catedráticos de escuelas universitarias, y dos de los indicados períodos los catedráticos de universidad. Actuaría de presidente el catedrático de universidad más antiguo, o en su defecto, el profesor titular de universidad o catedrático de escuela universitaria más antiguo (Art., 57). El propio Grupo Popular presentó una enmiendas en el sentido de que uno de los miembros de las comisiones pudiera ser investigador perteneciente a las escalas del CSIC.

La habilitación de los profesores titulares de universidad constaría de tres pruebas. La primera consistiría en la presentación y discusión con la comisión de los méritos e historial académico, docente e investigador del candidato, así como de su proyecto docente e investigador, que incluiría el programa de una de las materias o especialidades del área de conocimiento correspondiente. La segunda consistiría en la exposición y debate con la comisión de un tema del programa elegido por el candidato entre tres sacados a suerte. La tercera prueba consistiría en la exposición y debate de un trabajo original de investigación (Art.
59). La habilitación de catedrático de universidad constaría de dos pruebas. La primera consistiría en la presentación y discusión de los méritos e historial académico, docente e investigador del candidato, y la segunda en la presentación y debate de un trabajo original de investigación. Para obtener esta habilitación sería necesario tener la condición de profesor titular de universidad o catedrático de escuela universitaria con tres años de antigüedad; si bien el Consejo de Coordinación Universitaria, previo informe de la Comisión Nacional de Evaluación y Acreditación, podría eximir de este requisito a doctores con méritos excepcionales (Art. 60) el propio Grupo Popular presentó un enmienda substituyendo la expresión "méritos excepcionales" por "con, al menos, dos años de antigüedad"). El Consejo de Coordinación Universitaria señalaría el número de habilitaciones que serían objeto de convocatoria en cada área de conocimiento a fin de garantizar la posibilidad de selección de las universidades entre los habilitados. Las Comisiones de Habilitación no podrían proponer la habilitación de un número mayor de candidatos; pero si inferior, incluso la no habilitación de candidato alguno (Art. 62).

Los concursos de acceso a las plazas concretas serían convocados por las correspondientes universidades y resueltos en cada universidad por una comisión constituida a tal efecto, de acuerdo con el procedimiento previsto en sus estatutos. En dichos concursos podrían participar, junto a los habilitados para el cuerpo de que se tratase, los funcionarios de dicho cuerpo y los de cuerpos docentes universitarios superiores. Los concursos de acceso podrían resolverse con la no provisión de plaza durante un plazo máximo de dos años; a partir de este momento, de existir concursante, no sería posible dejar la plaza vacante (Art. 63).

En las pruebas de habilitación y en los concursos de acceso quedarían garantizados, en todo momento, la igualdad de oportunidades de los candidatos y el respeto a los principios de mérito y capacidad de los mismos (Art. 64). Podrían presentarse reclamaciones tanto contra las propuestas de las Comisiones de Habilitación como contra las propuestas de las Comisiones de los concursos de acceso (Art. 66).

Por lo que se refiere al personal docente e investigador contratado, el proyecto de ley establecía seis figuras: ayudante, profesor ayudante doctor, profesor colaborador, profesor contratado doctor, profesor asociado y profesor visitante. El número total de dicho personal no podría superar el $49 \%$ del total del profesorado de la universidad. La contratación la realizarían las universidades mediante concursos públicos. La selección se efectuaría con respeto a los 
principios de igualdad, méritos y capacidad; considerándose mérito preferente estar habilitado. Las universidades podrían contratar, además, en régimen laboral, profesores eméritos entre funcionarios públicos de los cuerpos docentes que hubieran prestado servicios destacados (Art. 48).

En cuanto al régimen retributivo, el proyecto de Ley establecía que el mismo sería uniforme en todas las universidades públicas en el caso de los profesores funcionarios; si bien el gobierno podría establecer retribuciones adicionales ligadas a méritos docentes, investigadores y de gestión. Por otra parte, los Consejos Sociales de las universidades podrían acordar de manera singular e individualizada la asignación de complementos retributivos en atención a exigencias docentes, investigadoras y de gestión de especial relevancia (Art. 69). El régimen retributivo del profesorado contratado de las universidades públicas sería regulado por las Comunidades Autónomas; si bien el gobierno podría establecer programas de incentivos docente e investigador que incluyeran dicho profesorado. Como en el caso del profesorado funcionario, la Consejos Sociales de las universidades podrían asignar complementos retributivos individualizados (Art. 55). Finalmente, cabe mencionar que el proyecto de LOU determinaba la creación de una Agencia Nacional de Evaluación y de Acreditación que, entre otros objetivos, tendría la evaluación, certificación y acreditación de las actividades docentes, investigadoras y de gestión del profesorado universitario (Arts. 31 y 32).

Iniciado el curso el mes de septiembre, las asociaciones estudiantiles anunciaron que convocarían manifestaciones y huelgas generales a partir de octubre, para pedir la retirada del proyecto de LOU. Por su parte la CRUE decidió hacer llegar sus propuestas de modificaciones del proyecto de ley a los grupos parlamentarios para que pudieran incluirlas en las enmiendas que presentaran (162). Finalizado el plazo de presentación de enmiendas a la totalidad, habían llegado al Congreso ocho enmiendas de devolución y una enmienda con propuesta alternativa del Grupo Parlamentario Socialista ${ }^{163}$. Dicha propuesta incluía los mismos cuerpos de funcionarios docentes que el proyecto del gobierno, y preveía que el ingreso en los mismos se realizaría en dos fases: acreditación y concurso de acceso.

La acreditación, que certificaría la posesión de los méritos docentes e investigadores suficientes para formar parte del correspondiente cuerpo, sería otorgada por la Agencia Española de Evaluación y Acreditación. A tal fin, se constituirían comisiones por área de conocimiento, formadas por siete profe- sores y presididas por un catedrático de universidad. Los miembros de dichas comisiones, renovados anualmente, deberían poseer el menos el reconocimiento de dos períodos de actividad investigadora. Para obtener la acreditación, los aspirantes deberían presentar ante la correspondiente comisión su curriculum docente e investigador; siendo los méritos docentes avalados por las universidades en las que hubieran desarrollado tareas docentes (Art. 52).

Los concursos de acceso a plazas concretas serían convocados por la universidad correspondiente; serían públicos y constarían de dos pruebas idénticas a las previstas por la LRU el propio PSOE en una enmienda particular propuso que las universidades pudieran establecer una prueba adicional en relación con el proyecto docente presentado por el candidato). Los concursos serían resueltos por Comisiones compuestas por cinco profesores del área de conocimiento, de los cuales el presidente sería siempre un catedráticos de universidad designado por la propia universidad. Los otros miembros serían un catedrático y tres profesores titulares de universidad, o cuatro catedráticos de universidad, según el caso, designados todos ellos por sorteo. Para poder concursar a plazas de catedrático de universidad sería necesario tener dicha condición o bien la de profesor titular de universidad o catedrático de escuela universitaria con tres años de antigüedad; si bien el Consejo de Universidades podría eximir de este requisito a doctores, a atención a sus méritos (Art. 55 y 56).

La propuesta presentada por el PSOE mantenía la posibilidad de proveer plazas mediante concurso de méritos, ya prevista en la LRU; si bien dejaba en manos de los estatutos de cada universidad la normativa referente a la constitución de las correspondientes comisiones (Art. 58). Por otra parte, la propuesta indicaba que, para favorecer la movilidad del profesorado y la incorporación de investigadores a las enseñanzas universitarias, las universidades deberían cubrir un $15 \%$ del total de sus plazas de funcionario docente con candidatos que hubieran desarrollado sus tareas docentes o investigadoras en centros de investigación o universidades distintas de aquella que convoca la correspondiente plaza (Art, 57).

Por lo que se refiere al personal docente e investigador contratado en régimen laboral, la propuesta presentada por el PSOE incluía las mismas figuras que el proyecto del gobierno, excepto la de profesor contratado doctor que quedaba englobada en la figura de profesor colaborador (Art. 42). El total del profesorado contratado no podría superar el $30 \%$ del total del profesorado de la universidad (en una enmienda par- 
ticular el propio PSOE elevaría este porcentaje al $40 \%)$. La contratación se haría mediante concursos, en los que se consideraría como mérito preferente estar acreditado (Art. 43). Respecto al régimen de retribución del profesorado, tanto funcionario como contratado, la propuesta no difería del proyecto del gobierno.

Digamos, finalmente, que el proyecto de ley del PSOE incluía un título sobre "Espacio Europeo de la Enseñanza Superior" en el que se afirmaba que el profesorado de las universidades de los países de la Unión Europea que hubiese alcanzado una posición equivalente a las de catedrático o profesor titular de universidad sería considerado acreditado a los efectos previstos en la Ley, y podría formar parte de las comisiones de acreditación y de las comisiones encargadas de resolver los concursos para el acceso a los cuerpos docentes universitarios. Por otra parte, los nacionales de Estados miembros de la Unión Europea así como los nacionales de aquellos Estados con tratados de libre circulación de trabajadores ratificados por España podrían participar en las pruebas de acreditación y en los concursos de acceso a los cuerpos de funcionarios docentes universitarios, así como en los concursos de contratación de profesores, con tratamiento idéntico al de los nacionales españoles.

El día 27 de septiembre se reunió el pleno del Congreso de Diputados para celebrar el debate de las enmiendas a la totalidad presentadas al proyecto de LOU. Los portavoces de todos los grupos parlamentario, con la excepción de los del Partido Popular y Coalición Canaria, criticaron el proyecto. Pero tanto las ocho enmiendas de devolución como el texto alternativo presentado por el PSOE fueron rechazadas, con los votos a favor de los grupos antes mencionados y la abstención del Grupo Parlamentario Catalán ${ }^{164}$. El día 2 de octubre, la ministra a propuesta de dos grupos parlamentarios, compareció ante la Comisión General de las Comunidades Autónomas del Senado, para informar sobre al anteproyecto de LOU antes de que la cámara tuviera que debatirlo ${ }^{165}$. Dos días después finalizó el plazo de presentación de enmiendas parciales, que totalizaron más de ochocientas ${ }^{163}$, y el día 9 se creó la Ponencia de la Comisión de Educación del Congreso de Diputados que debía debatirlas.

El Grupo Socialista presentó más de doscientas enmiendas parciales, de acuerdo con los contenidos de su texto alternativo rechazado días antes. El Grupo Federal de Izquierda Unida propuso enmendar todos los artículos del proyecto de LOU referentes al profesorado de las universidades públicas. Propuso una estructura más simplificada para el personal docente e investigador; distinguiendo entre personal en formación (ayudantes y personal investigador en formación) y profesorado permanente (profesores colaboradores, profesores titulares, catedráticos, profesores asociados y profesores visitantes). Sólo los profesores titulares y los catedráticos serían funcionarios. El acceso a la condición de profesor titular requeriría la previa habilitación mediante concursos convocados por el estado, por una o varías comunidades autónomas y por una o varías universidades, con validez para el ámbito correspondiente, y resueltas, atendiendo únicamente a los méritos académicos de cada concursante y sin limitación numérica, por comisiones formadas por especialistas de distintas universidades de la Unión Europea. La adscripción a una plaza de funcionario se realizaría por concurso resuelto por una comisión de la misma universidad, atendiendo a la idoneidad para las tareas a realizar. Las instancias antes mencionadas podrían convocar concursos de habilitación entre profesores titulares para la categoría de catedrático, que serían resueltos por comisiones formadas por especialistas de distintas universidades de la Unión Europea que tuvieran la condición de catedrático o equivalente. El grupo Iniciativa per Catalunya-Els Verds presentó varías enmiendas en el sentido de mantener el proceso de habilitación como requisito para participar en los concursos de acceso a cuerpos de funcionarios convocados por las universidades; pero eliminando toda la normativa específica.

El Grupo Catalán propuso muy pocas enmiendas al Título IX del proyecto de LOU; entre ellas, la de exigir únicamente "tener la condición de doctor con, al menos, ocho años de antigüedad" para poder obtener la habilitación para el cuerpo de catedráticos de universidad. El Grupo Vasco propuso numerosas enmiendas al articulado sobre profesorado, dirigidas a ajustar la ley al régimen constitucional de reparto de competencias entre poderes públicos. En este sentido, propuso suprimir todos los artículos referentes a las diversas figuras de personal docente e investigador contratado, y modificar la mayoría de los artículos referentes al profesorado de los cuerpos docentes. Por lo que se refiere al proceso de habilitación, al que propuso denominar de acreditación, presentó diversas enmiendas para atribuir a las Comunidades Autónomas su convocatoria y gestión. Entre otras cosas, propuso que los miembros de las comisiones deberían estar adscritos a las universidades del ámbito territorial correspondiente, y que a las convocatorias sólo podrían acceder los candidatos que tuvieran su residencia en el territorio de la correspondiente Comunidad. No presentó enmiendas relativas a las pruebas de dicho proceso. Eusko Alkartasuna propu- 
so varías enmiendas, la mayoría de supresión de diversos artículos, entre los cuales se hallaban los referentes a las diversas figuras del profesorado contratado y los referentes a las pruebas de habilitación. De acuerdo con sus propuestas, la LOU debería prácticamente limitarse a precisar los tipos de profesorado contratado y funcionario, y a indicar que serían las universidades, de acuerdo con las Comunidades Autónomas, quienes establecerían los correspondientes mecanismos de selección. El Bloque Nacionalista Galego presentó enmiendas en el sentido de que la LOU se limitara a indicar que para poder participar en los concursos de provisión de plazas de los cuerpos docentes universitarios haría falta haber obtenido una acreditación previa otorgada por las Agencias de Evaluación y Acreditación de las Comunidades Autónomas. El Partido Andalucista presentó una enmienda en el sentido de precisar que las pruebas de habilitación en ningún caso establecerían un numerus clausus, y la Junta Aragonesista presentó otra enmienda para suprimir el requerimiento de que, de haber candidatos, las universidades se vieran obligadas a cubrir en un período máximo de dos años las plazas convocadas a concurso. El Grupo de Coalición Canaria propuso varías enmiendas; entre otras las de establecer convocatorias de habilitación anuales y sin límite de habilitados. Por otra parte, propuso que, aparte del gobierno, las Comunidades Autónomas pudieran establecer retribuciones adicionales ligadas a méritos individuales docentes, investigadores y de gestión; correspondiendo a los Consejos Sociales la asignación individual de dichos complementos, previa valoración externa de los méritos. Finalmente, Esquerra Republicana de Catalunya no presentó ninguna enmienda al Título IX del Proyecto de LOU.

Es de destacar que sólo hubo una enmienda, presentada por Coalición Canaria, en el sentido de "rescatar de su secular olvido la importancia de la actividad docente del profesorado universitario", de forma que la dedicación a la docencia y la preparación y formación pedagógica para mejorar su calidad constituyeran aspectos tan valorados como los méritos y dedicación investigadora a la hora de evaluar la actividad del profesorado universitario.

La Ponencia nombrada por la Comisión de Educación, Cultura y Deportes del Congreso de Diputados emitió su informe el día 18 de octubre (166). De acuerdo con dicho informe, se confería un mayor protagonismo a la Comunidades Autónomas y, por lo que hace al Titulo IX sobre Profesorado, se incorporaban todas las enmiendas del Grupo Popular, cuatro enmiendas propuestas por Coalición Canaria, tres presentadas por el Grupo Catalán, otras tres por Iniciativa per Catalunya-Els Verds,y una propuesta por el PSOE. Por otra parte, se incorporaba en forma de enmienda transaccional el título del proyecto del PSOE sobre "Espacio Europeo de Enseñanza Superior", antes mencionado, previo ajuste de la redacción definitiva. Después de rechazar, por los votos del Partido Popular, la comparecencia de expertos ante la Comisión, solicitada por el PSOE y por Izquierda Unida, y haciendo caso omiso de una petición de la CRUE que reclamaba una tramitación parlamentaria congruente con la importancia del Proyecto de LOU ${ }^{167}$, la Comisión debatió el informe emitido por la Ponencia y las enmiendas correspondientes, en una sesión maratoniana de casi diecisiete horas, que comenzó el día 22 de octubre y acabó a las cuatro de la madrugada del día 24 . Sólo once enmiendas de las más de seiscientas debatidas se incorporaron al texto final ${ }^{168}$.

Mientras tanto, las manifestaciones de rechazo del proyecto de ley habían aumentado. Un dictamen encargado por las universidades catalanas ${ }^{169}$ consideró anticonstitucionales cinco artículos del texto del gobierno, y un informe elaborado por expertos juristas universitarios ${ }^{170}$ lo criticó duramente; afirmando, por lo que respecta al procedimiento de habilitación, que era centralizador y poco constitucional. La mayoría de los claustros de las universidades públicas habían manifestado su repulsa unánime ${ }^{147}$. Unos seis mil quinientos profesores universitarios habían suscrito dos manifiestos entregados al Congreso de los Diputados, solicitando la retirada del proyecto y el retraso de su aprobación hasta que se hubiese alcanzado el consenso necesario. Los representantes de treinta asociaciones de estudiantes acordaron convocar movilizaciones durante la tercera semana de noviembre y realizar una huelga general el día 14 del mismo mes. Los sindicatos también decidieron convocar otra huelga universitaria una semana antes que los estudiantes.

Pese a todo, el Proyecto de LOU dictaminado por la Comisión de Educación, Cultura y Deportes ${ }^{171}$ fue aprobado el día 31 de octubre por el Pleno del Congreso de Diputados ${ }^{172}$ con los votos del PP, CiU y Coalición Canaria, mientras estudiantes y profesores hacían oír su voz en contra, en manifestaciones masivas celebradas en Madrid y otras ciudades. Con fecha 6 de noviembre, el texto aprobado por el Congreso tuvo su entrada en el Senado ${ }^{173}$; fue remitido a la Comisión de Educación Cultura y Deportes de la cámara y se abrió un plazo para la presentación de enmiendas hasta el día $19^{174}$. Un día antes, la CRUE y los sindicatos CCOO y UGT, después de celebrar 
una reunión conjunta, habían hecho público un comunicado dirigido al Presidente del Gobierno pidiéndole que aprovechara la última oportunidad que ofrecía el Senado para abrir un proceso de diálogo y buscar el consenso sobre la LOU. El día 7 de noviembre tuvo lugar la huelga general universitaria contra el proyecto de LOU convocada por los sindicatos y con un seguimiento del $90 \%$ según éstos; más de cien mil profesores universitarios (entre ellos varios rectores), estudiantes y personal no docente se manifestaron en la calle. Pero la movilización fue todavía mayor el día 14 cuando, respondiendo a la convocatoria de las asociaciones, más de doscientos mil estudiantes se manifestaron en unas cincuentas ciudades españolas. Sin embargo, la ministra aseguró que no existía "clamor unánime" contra la LOU, y atribuyó las críticas a la ley a "una lucha de poderes".

A pesar de las propuestas de veto presentadas por varios grupos parlamentarios ${ }^{175}$, y de la petición de la CRUE de retirar el proyecto de LOU ${ }^{176,177}$, la tramitación parlamentaria siguió su curso. Los días 29 y 30 de noviembre, en escasamente doce horas, tuvo lugar en la Comisión de Educación, Cultura y Deportes del Senado el debate sobre el informe emitido por la Ponencia ${ }^{178}$, las seis enmiendas a la totalidad y las más de seiscientas enmiendas particulares presentadas por prácticamente todos los grupos políticos ${ }^{179}$. Se introdujeron en el texto sesenta y siete enmiendas; sólo quince de la oposición y todas ellas de matiz. Por lo que respecta al Título IX, la Comisión del Senado no realizó ninguna modificación importante. Cabe mencionar únicamente que se precisó que junto a la Agencia Nacional de Evaluación de la Calidad y Acreditación, el órgano de evaluación externa que la Ley de la correspondiente Comunidad Autónoma determinara podría participar en la valoración previa a la asignación de los correspondientes complementos retributivos por méritos individuales docentes, investigadores y de gestión (Art.55 y 69). Por otra parte, se estableció que el sistema de habilitación entraría en vigor el día siguiente de la publicación de la Ley en el BOE ( no a la entrada en vigor de la misma, que era a los veinte días de su publicación) y que las convocatorias de plazas que no estuvieran publicadas al producirse la publicación de la LOU se regirían por el nuevo sistema . Al día siguiente, el 1 de diciembre, las peticiones de retirada del Proyecto de LOU culminaron con una gran manifestación en Madrid (con 350.000 participantes según los organizadores, o 50.000 según el Ministerio) en la que estuvieron presentes veinticinco rectores junto a sus alumnos, profesores, personal no docente y políticos de toda España. Doce días después hubo nuevas manifestaciones en distintas ciudades; pero entonces la movilización fue mucho menor. Por entonces, casi nueve mil profesores universitarios, entre ellos seiscientos cincuenta catedráticos, habían firmado el manifiesto contra la LOU y numerosos claustros universitarios habían solicitado la retirada de la misma.

El Proyecto de LOU llegó al Pleno del Senado el 13 de diciembre. Antes del comienzo todos los grupos de la oposición comparecieron ante los medios de comunicación para presentar un comunicado conjunto en el que denunciaban "el abuso ejercido por la mayoría absoluta del Partido Popular" durante el trámite parlamentario de la Ley. Finalizado el debate, con los votos del PP, CiU y Coalición Canaria, se aprobó el Proyecto de LOU ${ }^{180-182}$, que al haber sido modificado por la incorporación de ochenta enmiendas, la mayoría propuestas por el Grupo Popular, volvió al Congreso de Diputados para su aprobación definitiva ${ }^{183}$.

Mientras tenían lugar diversas manifestaciones, paros, acampadas y otras protestas estudiantiles en un intento de frenar la aprobación final de la LOU, el día 20 de diciembre culminaba la tramitación parlamentaria de la ley, al ser aprobada por el Pleno del Congreso de Diputados, con el respaldo de los mismos grupos que la habían aprobado en el Senado ${ }^{184,185}$. Después de ser aprobada definitivamente por el Consejo de Ministros al día siguiente, la LOU aparecía en el BOE el día 24 de diciembre ${ }^{186}$, para entrar en vigor veinte días después, el 13 de enero del año 2002. Pero las asociaciones de estudiantes ya habían anunciado que seguirían convocando movilizaciones y la CRUE había manifestado que no renunciaba a un modelo de Universidad distinto del configurado por la Ley ${ }^{187}$. A lo largo del año, las universidades habían convocado a concurso unas nueve mil quinientas plazas de profesor ordinario (la mitad de ellas a partir de mediados de noviembre) que al haberse publicado en el BOE antes de la LOU no deberían ajustarse a la nueva normativa que al misma establecía. Según la prensa, el gobierno pensó en anular la convocatoria de estas plazas mediante un decreto u otra fórmula jurídica, como una disposición transitoria; pero, finalmente, no fue así ${ }^{188}$.

BIBLIOGRAFÍA (2a parte, continuación)

Las referencia 1 a 116 se encuentran, en la primera parte del artículo (volumen 7 número 1). La referencia 116 debe completarse añadiendo: Documento de trabajo. Facultad de Psicología, Universitat de Barcelona, 2001.

117. Rodríguez A. Debate en el "campus" El Pais Educación 1990; 381: 1 y 3 . 
118. Los rectores y la reforma. El País Educación 1991; 435: 1.

119. Bricall JM, Vallés JM, Ferraté G. Argulloll E. La reforma de la reforma El País Educación 1991; 435: 5.

120. Díaz C. Los argumentos de los rectores. El País Educación 1991;435: 3

121. Barcia E. La alternativa del PP. El País Educación 1991; 435: 4

122. Blanco C. Dos por uno. El País Educación 1992; 451: 1 y 4.

123. Proyecto de ley de Actualización de la Ley Orgánica 11/1983. Boletín Oficial de las Cortes Generales, Congreso de los Diputados, IV Legislatura, Serie A, Núm. 99-1 (14IX-1992).

124. Proyecto de Ley de Actualización de la Ley Orgánica 11/1983. Enmiendas. Boletín Oficial de las Cortes Generales, Congreso de los Diputados, IV Legislatura, Serie A, Núm.996 (3-XI-1992).

125. Sesión Plenaria. Cortes Generales, Diario de Sesiones del Congreso de los Diputados, Pleno y Diputación Permanente, Año 1992, IV Legislatura, Núm. 227 (12-XI-1992),pp.1127011292.

126. Proyecto de Ley de Actualización de la Ley Orgánica. 11/1983. Informe de la Ponencia. Boletín Oficial de las Cortes Generales, Congreso de los Diputados, IV Legislatura, Serie A, Núm. 99-10 (26-XI-1992).

127. Proyecto de Ley de Actualización de la Ley Orgánica 11/1983. Dictamen de la Comisión. Boletín Oficial de las Cortes Generales, Congreso de los Diputados, IV Legislatura, Serie A, No 99-11 (10-XII-1992).

128. Comisión de Educación y Cultura. Cortes Generales. Diario de Sesiones del Congreso de los Diputados, Año 1992, IV Legislatura, Núm. 582 (15-XII- 1992), pp. 17520-17551.

129. Comisión de Educación y Cultura. Cortes Generales. Diario de Sesiones del Congreso de los Diputados, Año 1992, IV Legislatura, Núm. 587 (16-XII-1992), pp. 17666-17689.

130. Sesión Plenaria. Cortes Generales, Diario de Sesiones del Congreso de los Diputados, Pleno y Diputación Permanente, Año 1992, IV Legislatura, Núm. 244 (11-II-1993), pp. 12345-

131. Proyecto de Ley de Actualización de la Ley Orgánica 11/1983. Aprobación por el Pleno. Boletín Oficial de las Cortes Generales. Congreso de los Diputados, IV Legislatura, Sección A, Núm.99-12 (12-II-1993).

132. Comisión de Educación, Universidades, Investigación y Cultura. Cortes Generales. Diario de Sesiones del Senado, Año 1993, IV Legislatura, Núm. 256 (25-III-1993), pp. 2-37.

133. Sesión Plenaria. Cortes Generales, Diario de Sesiones del Senado, Año 1993, IV Legislatura, Núm. 159 (31-III-1993), pp. 8783-8825.

134. Proyecto de Ley de Actualización de la Ley Orgánica 11/1983. Boletín Oficial de las Cortes Generales. Senado, IV Legislatura, Serie II (6-IV-1998).

135. Proyecto de Ley de Actualización de la Ley Orgánica 11/1983, de 25 de agosto, de Reforma Universitaria. Boletín
Oficial de las Cortes Generales, Congreso de los Diputados, V Legislatura, Serie A, Núm. 65-I (27-V-1994).

136. Mederos A. Otro sistema de selección. El País Educación. 1994; 535: 4-5.

137. Proyecto de Ley de Actualización de la Ley Orgánica 11/1983. Enmiendas. Boletín Oficial de las Cortes Generales, Congreso de los Diputados, V Legislatura, Serie A, Núm. 6510 (24-X-1994).

138. Sesión Plenaria. Cortes Generales, Diario de Sesiones del Congreso de los Diputados, Pleno y Diputación Permanente, Año 1994, V Legislatura, Núm. 89 (15-IV-1994), pp. 4611-4628.

139. El País, de 16-VI-1995, p.25.

140. El País, de 20-I-1998, p.32.

141. Gaceta Universitaria, de 25-V-98, p. 11.

142. El País, de 17-XII-98, p.30.

143. Comissió de Reflexió sobre el futur de l'ambit universitari català. Per un nou model d'universitat. Generalitat de Catalunya. Barcelona, 2001.

144. El País, de 19-III-2001, p. 30.

145. Intervención de la Ministra de Educación, Cultura y Deporte al ante el Pleno del Consejo de Universidades (19-4-01). http:/www.crue.org/ley universid.htm

146. Anteproyecto de la Ley Orgánica de Universidades (7-05-01). http://www.crue.org/ley universid.htm

147. Ley de Ordenación Universitaria. Universidades. http:// www.crue.org/ley universid.htm

148. Texto acordado por la Asamblea General de la CRUE (21-052001). http://www.crue.org/ley universid.htm

149. Acuerdo de la Asamblea General de la CRUE (15-06-01). http://www.crue.org/ley universid.htm

150. Comisión de Educación, Cultura y Deportes. Sesión Núm 16. Cortes Generales. Diario de Sesiones del Congreso de los Diputados, Año 2001, VII Legislatura, Núm. 241 (29-052001), pp.3620-3649.

151. Comparecencia de la Ministra de Educación, Cultura y Deportes en la Comisión del Senado para informar sobre los borradores de los proyectos de Ley de Universidades y Formación Profesional (12-06-01). http://www.crue.org/ley universid.htm

152. Intervención de la Sra. Ministra sobre el Anteproyecto de la Ley de Universidades en el Pleno del Consejo de Universidades (21-06-01) http://www.crue.org/leyuniversid.htm.

153. Anteproyecto de Ley Orgánica de Universidades (12-07-01). http:// www.crue.org/ley universid.htm

154. Solicitud de audiencia de las universidades públicas madrileñas actuando por cuenta y en beneficio de las restantes Universidades. http://www.crue.org/ley unicersid.htm

155. Dictamen del Consejo de Estado sobre el anteproyecto de Ley Orgánica de Universidades (19-07-01). http:// www.crue.org/ley universid.htm

156. Proyecto de Ley Orgánica de Universidades. Boletín Oficial 
de las Cortes Generales, Congreso de los Diputados, VII Legislatura, Serie A, Núm. 45-I ( 31-07-01).

157. Una Universidad para la sociedad del conocimiento. Proyecto alternativo del Partido Socialista al anteproyecto de Ley Orgánica de Universidades, elaborado por el Ministerio de Educación, Cultura y Deporte. http://crue org/ley universid.htm.

158. Comunicado de la CRUE (27-07-01). http://www.crue.org/ley universid.htm.

159. G. Tortella Carta abierta a la ministra de educación sobre la Ley de Reforma Universitaria. El País, de 9-06-01, p. 27

160. Manifiesto contra el anteproyecto de L.O.U. y por una universidad autónoma que siga avanzando en la calidad de su enseñanza y de su investigación. http://www.crue.org/ley universid.htm.

161. A la opinión pública y a José Maria Aznar. Manifiesto contra el Proyecto de la Ley Orgánica de Universidades. http:// www.crue.org/ley universid.htm.

162. Nota sobre el Proyecto de Ley de Universidades dirigida a los Grupos Parlamentarios por la CRUE (19-09-01). http://www.crue.org/ley universid.htm.

163. Ley Orgánica de Universidades. Enmiendas. Boletín Oficial de las Cortes Generales, Congreso de los Diputados, VII Legislatura, Serie A, Núm.45-5 (13-X-01).

164. Sesión Plenaria. Cortes Generales, Diario del Sesiones del Congreso de los Diputados, Plenario y Diputación Permanente, Año 2001,VII Legislatura, Núm. 108 (27-09-2001), pp. 52555280 .

165. Cortes Generales. Diario de Sesiones del Senado. Comisión General de las Comunidades Autónomas, Año 2001, VII Legislatura. Comisiones, Núm. 174 (9-X-2001), pp. 1-43.

166. Ley Orgánica de Universidades. Informe de la Ponencia. Boletín Oficial de las Cortes Generales. Congreso de los Diputados, VII Legislatura, Serie A, Núm. 45-7 (22-X2001).

167. Acuerdo de la Asamblea General de la CRUE (17-X-2001). http://www.crue.org/ley universid.htm

168. Ley Orgánica de Universidades. Dictamen de la Comisión. Boletín Oficial de las Cortes Generales, Congreso de los Diputados, VII Legislatura, Serie A, Núm 45-8 (29-X-2000).

169. Dictamen sobre el projecte de Llei Orgànica d'Universitats en relació a la seva incidència en las competèncias atribuides a les comunitats autònomas i en principi d'autonomia universitària. http://www.crue.org/ley universid.htm

170. Informe Anteproyecto de la Ley Orgánica de Universidades del grupo de asesores jurídicos de universidades. http://www.crue.org/ley universid.htm

171. Sesión Plenaria Cortes Generales. Diario del Congreso de los Diputados, Pleno y Diputación Permanente, Año 2001, VII Legislatura, Núm. (31-X-2001) pp 5651-5701.
172. Ley Orgánica de Universidades. Aprobación por el Pleno. Boletín Oficial de las Cortes Generales. Congreso de los Diputados, VII Legislatura, Serie A Núm. 45-11 (8-XI-2001).

173. Proyecto de Ley Orgánica de Universidades. Texto remitido por el Congreso de los Diputados. Boletín Oficial de las Cortes Generales. Senado, VII Legislatura, serie II, Núm. 37 (a) (6-X-2001).

174. Proyecto de la Ley Orgánica de Universidades. Enmiendas. Boletín Oficial de las Cortes Generales. Senado, VII Legislatura, Serie II. Núm. 37 (d) ( 28-XI-2001).

175. Proyecto de Ley Orgánica de Universidades. Propuestas de reto. Boletín Oficial de las Cortes Generales. Senado, VII Legislatura, Serie II, Núm 37 (c) (28-XI-2001)

176. Comunicado de la CRUE (14-XI-2001). http://www.crue.org/ ley universid htm.

177. Comunicado de la CRUE tras su asamblea general. (26-XI2001) htpp://www.crue.org/ley universid.htm.

178. Proyecto de la Ley Orgánica de Universidades. Informe de la Ponencia. Boletín Oficial de las Cortes Generales, Senado, VII Legislatura, Serie II, Núm.37 (f) (29-XI-2001).

179. Proyecto de la Ley Orgánica de Universidades. Dictamen de la Comisión. Boletín Oficial de las Cortes Generales, Senado, VII Legislatura, Núm 37 (g) (7-XII-2001).

180. Sesión del Pleno. Cortes Generales. Diario de Sesiones del Senado, Año 2001, VII Legislatura, Núm 70 (13-XII-2001), pp. 4038-4131.

181. Sesión del Pleno. Cortes Generales. Diario de Sesiones del Senado, Año 2001, VII Legislatura, Núm. 71 (14-XII-2001), pp. 4132-4181.

182. Proyecto de ley Orgánica de Universidades. Texto aprobado por el Senado. Boletín Oficial de las Cortes Generales, Senado, VII Legislatura, Serie II, Núm. 37 (h) (19-XII-2001).

183. Enmiendas del Senado mediante mensaje motivado al Proyecto de la Ley Orgánica de Universidades. Boletín Oficial de las Cortes Generales, Congreso de los Diputados, VII Legislatura, Serie A, Núm. 45-12 (19-XII-2001).

184. Sesión Plenaria. Cortes Generales, Diario de Sesiones del Congreso de los Diputados, Pleno y Diputación Permanente, Año 2001, VII Legislatura, Núm. 132 (20-XII-2001), pp. 6639-6654.

185. Ley Orgánica de Universidades. Aprobación del proyecto por el Congreso. Boletín Oficial de las Cortes Generales, Congreso de los Diputados, VII Legislatura, Serie A, Núm. 45-13 (26-XII-2001).

186. Ley Orgánica 6/2001, de 21 de diciembre, de Universidades (B.O.E. de 24-XII-2001).

187. Nota de prensa de la CRUE (26-XII-01). http://www.crue. org/ley universid.htm

188. Ortega J. El MEC busca una salida a la "jugada" de los rectores. Gaceta Universitaria, de 17-XII-2001, pp .4-5. 